\title{
Nurses' turnover intention, hope and career identity: the mediating role of job satisfaction

\author{
Huiling $\mathrm{Hu}^{\dagger}$, Chongkun Wang ${ }^{\dagger}$, Yue Lan and Xue Wu+(D)
}

\begin{abstract}
Background: A high turnover rate has become a critical issue in the field of nursing and how to tackle the problem of nursing turnover has received increased attention worldwide. Hope, career identity, job satisfaction may be useful for reducing turnover. The aim of this study is to explore the relationships among career identity, hope, job satisfaction, and the turnover intention of nurses, and to test the mediating role of job satisfaction on the associations of hope and career identity with turnover intention.

Methods: A descriptive cross-sectional design was used. A total of 500 nurses were recruited from five comprehensive tertiary hospitals using convenience sampling. The questionnaire included items about sociodemographic information as well as the Adult Dispositional Hope Scale, Nursing Career Identity Scale, Job Satisfaction Index Scale, and Nurse Turnover Intention Scale. Pearson's correlation, multiple linear regression, and structural equation modeling were used to analyze the data. We describe the study in accordance with the STROBE statement.

Results: Hope $(r=-0.227, p<0.001)$ and career identity $(r=-0.342, p<0.001)$ were negatively correlated with turnover intention. Job satisfaction played a completely mediating role on the associations of hope and career identity with turnover intention $\left(\beta_{1}=-0.09, \beta_{2}=-0.33\right)$.

Conclusions: Job satisfaction mediated the associations of career identity and hope with turnover intention. Thus, effective measures can be taken to enhance nurses' hope and career identity in order to improve their job satisfaction and thereby reduce their turnover intention. Providing nurses with more support, helping them find a spiritual foundation, and holding mindful activities that stimulate positive emotions are helpful. In addition, colleges should pay more attention to instilling nursing students with career identity and nursing values.
\end{abstract}

Keywords: Personnel turnover, Hope, Career identity, Job satisfaction, Nurses, Mediating effect

\section{Background}

Nursing shortages have become a critical issue for healthcare systems all over the world [1-3]. Pressure on the healthcare system keeps growing because of the aging population and the increasing need of health services, which have greatly increased the demand for nurses [3-7]. When the "Healthy China 2030" initiative was implemented in China, there was an adequate reserve of nursing human resources to meet increasing demand.

*Correspondence: wuxue@bjmu.edu.cn

${ }^{\dagger}$ Huiling Hu and Chongkun Wang should be considered joint first author.

School of Nursing, Peking University, Beijing 100191, P.R. China
However, as the WHO reported, rising demand has exacerbated a global nursing shortage, which is predicted to exceed 7.6 million by 2030 [8]. Thus, the high turnover rate of nurses is a global concern $[2,5,9,10]$. Given the situation, the shortage of nurses will become more prominent. Though recruiting more nurses may help, retaining nurses in hospitals is another and potentially more effective method to cope with the problem of nursing shortages. Therefore, how to tackle the problem of nursing turnover has received increased worldwide attention [11, 12].

A high turnover rate has become a critical issue in the field of nursing. Intention to leave is an early indicator of 
actual turnover $[4,13]$, and one way to retain nurses is to reduce their turnover intention [1]. Turnover intention has been defined as "the last in a sequence of withdrawal cognitions, a set to which thinking of quitting and intent to search for alternative employment also belong" [14]. In simple terms, turnover intention indicates the intention to leave the job in a period ahead [15]. Turnover intention has been widely proved to be an important and practical antecedent variable of turnover, and it is the best predictor of actual turnover behavior [16]. Therefore, it is very important to identify the antecedents of turnover intention. A recent study reported that $22 \%$ of hospital nurses intended to leave their profession in less than a year because of workplace stress [17], and an earlier study reported that $15.5 \%$ of nurses intended to leave their profession [18]. Another study found $35-60 \%$ of nurses left their first place of employment within 1 year [19]. This can cause a shortage of clinical nurses, reduce nursing quality $[9,17]$, and increase re-recruitment costs [3]. A lower rate of nurse turnover is associated with safe and positive outcomes for patients [1]. Thus, it is critical to identity the key factors that influence and mediate nurses' turnover intention and to develop retention strategies tailored to nurses [7].

Turnover intention is affected by career identity, and a higher level of career identity usually indicates lower turnover intention among nurses [10,18]. Nurses' career identity can affect nurses' work enthusiasm and job satisfaction, so as to affect the quality of nursing $[20,21]$. Career identity is a relatively abstract concept, which refers to an individual's understanding of the social impact of his or her profession and the significance of his or her work [22], and involves the internalization of core values and perspectives [23]. It can be characterized by feelings, values, and attitudes [24]. Nurses' career identity is positively associated with job satisfaction [25]. When nurses positively identify with their careers, the dissatisfaction created by their work environment can be suppressed to a certain extent [26]. A study of 1312 hotel employees in China found that career identity has a positive impact on employees' job satisfaction and a negative impact on turnover intention [27]. It further explains the mediating role of job satisfaction between career identity and turnover intention. However, in the nurse group, this intermediary relationship has not been explored.

A study of 416 employees shows that there is a significant negative relationship between psychological capital and turnover intention [28]. Ayijiamali et al. and Zou et al. concluded that employees with good psychological capital will look positively at things in the organization, which largely depends on hope and optimism. More studies show that psychological capital has a direct and indirect impact on turnover intention through intermediary variables $[29,30]$. Hope belongs to a kind of psychological capital and has different meanings in different situations. Hope is a positive motivation state based on the inner sense of success. It includes will power, a kind of energy and path of goal orientation, that is, the way and plan to achieve the goal [31]. Scholars have shown that hope is particularly important in the face of the intense competition and uncertainty that characterize the present work and career environment [32]. A high level of hope helps nurses appropriately deal with psychological distress and cope with difficulties at work more positively, and it can motivate their pursuit of professional development. Thus, the negative impact of dissatisfaction with the job that generates intention to leave may be diminished. It means that their job satisfaction will be higher. Hope can lead to positive arousal and persistence in pursuit of one's goals (i.e., "energized to" motivation), which involves agency thinking, the confidence that one is capable of reaching one's goals ("can do" motivation), as well as pathway thinking, which are a critical psychological resource related to positive human development in various life domains, including vocational pursuits [32]. A study of workers in China found that hope was negatively correlated with turnover intention [33]. Although hope is increasingly recognized to be an important psychological resource for professional development, most studies have focused on the relationship between career and psychological capital, which combines hope with optimism, self-efficacy, and resilience into a somewhat ambiguous concept, and studies on the effects of hope on job satisfaction and turnover intention are rare.

Job satisfaction has a negative association with turnover intention $[2,34]$, which suggests that improving the job satisfaction of nurses could be an important strategy to retain them. The results of testing the turnover model show that job satisfaction is a significant antecedent of turnover intention. In other words, when employees' job satisfaction is low, they will increase the behavior indicating their intention to leave the organization $[35,36]$. Job satisfaction is usually defined as a positive and pleasurable emotional reaction generated by an individual's overall assessment [2]. Job satisfaction was first proposed by Hoppock et al. [37]. He believes that job satisfaction refers to an individual's psychological and physiological satisfaction with the work itself and the environment, and it is also an individual's subjective response to the work environment. Job satisfaction is an important part of organizational psychology and organizational behavior. Scanlan and Hazelton proposed that job satisfaction plays an intermediary role between career identity and employee turnover intention [25]. They believe that career identity enables employees 
to effectively obtain the required work resources, helps to create a comfortable working atmosphere, so as to improve employees' job satisfaction and reduce employees' turnover intention. It can be seen that career identity is the key factor affecting employees' job satisfaction. Therefore, we propose that job satisfaction can be used as an intermediary to explain its intermediary role between career identity and turnover intention behavior. Using job satisfaction as an intermediary can deepen our understanding of how career identity affects hotel employees' turnover intention. In addition, hope has been found to have a positive association with job satisfaction [38]. As career identity is closely related to self-efficacy, it may change attitudes towards work [39], so we can speculate that it may improve job satisfaction.

To sum up, the relationship between hope, career identity and turnover intention has been established in the literature. The research on the mediating role of job satisfaction in the relationship between hope, career identity and turnover intention is still very limited. Therefore, by combining the mediating role of job satisfaction, this study contributes to the literature on the relationship between hope, career identity and turnover intention. To our knowledge, there is no empirical study integrating these four variables into a model. We assumed that hope and career identity were negatively correlated with turnover intention, and that job satisfaction and turnover intention were negatively correlated. We hypothesized that job satisfaction plays a mediating role on the associations of hope and career identity with turnover intention. The hypothetical model we developed is shown in Fig. 1.

The purpose of this study was: (i) to investigate the turnover intention of nurses; (ii) to explore the relationships among career identity, hope, job satisfaction, and turnover intention; and (iii) to test the mediating effect of job satisfaction on turnover intention.

\section{Methods}

\section{Design and data collection}

This was a correlational study of 500 nurses who were recruited from comprehensive tertiary hospitals in Beijing using convenience sampling in June 2019. First, according to the convenience of sampling, we selected five comprehensive tertiary hospitals in Beijing, China. Then the nurses from all departments of the hospitals who were on duty on the survey day and were willing to cooperate with the survey were recruited. The inclusion criteria were as follows: (1) engaged in clinical work for more than 1 year; and (2) provided informed consent and volunteered to complete the questionnaires. Nurses studying in these hospitals were excluded. Trained volunteers handed out the questionnaires to potential participants, explained the purpose and principles of the study and the directions for completing the questionnaires, and obtained their informed consent. We received 493 valid questionnaires, for an effective completion rate of $98.6 \%$. Klien suggests that a sample size of 200 or more is required to yield stable estimates for testing structural equation models (SEM) [40]. According to 10 times the number of the scale items, the sample size is 495 . Considering a non-response rate of $10 \%$, a total of 500 nurses is enough. The participants were informed that their participation was completely voluntary and anonymous. We describe the research process of the study in accordance with the Strengthening the Reporting of Observational studies in Epidemiology (STROBE) statement [41].

\section{Measures}

\section{Sociodemographic characteristics}

The sociodemographic variables included gender, age, marital status, level of education, years of work, professional title, management position, and department.

\section{Hope}

Hope was measured with the Adult Dispositional Hope Scale (ADHS), which was developed by Snyder et al.

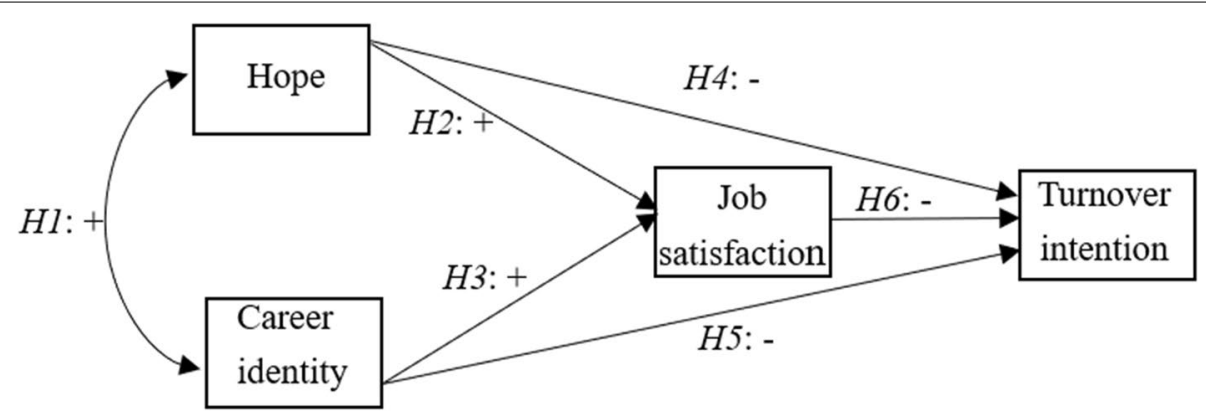

Fig. 1 Hypothesized model of relationship between hope, career identity, job satisfaction and turnover intention 
[42] and revised by Chen, Shen, and Li [43]. The ADHS measures three dimensions of hope: agency thinking (4 items), pathway thinking (4 items), and distraction (4 items). Agency thinking refers to a group of self-belief systems that initiate individual actions and support individuals to move forward toward their goals and along the established path. Path thinking is a group of beliefs and perceptions about one's ability to find effective ways to achieve desired goals [31]. The four questions of "distraction" are used to distract the subjects. Each item is rated from 1 to 4, except the distraction items, which are not rated. Higher scores indicate higher levels of hope. The Cronbach's $\alpha$ coefficients were 0.78 for the total score, 0.73 for agency thoughts, and 0.75 for pathway thoughts. And confirmatory structural analysis showed that it had good structural validity [43].

\section{Career identity}

The Nursing Career Identity Scale (NCIS) was developed by scholars at Tokyo University in Japan, and it has been widely used in Japan, Sweden, and other countries. Its cross-cultural adaptation and tests of its validity and reliability were conducted by Chinese scholars [44]. The 21 items of the NCIS measure seven dimensions, including sense of grasp ( 3 items), sense of consistency ( 4 items), sense of significance (3 items), sense of self efficacy (3 items), sense of self decision (3 items), sense of organizational influence ( 2 items), and sense of individual influence ( 3 items). All the items are rated on a 7 -point scale, ranging from 1 (extremely not conform) to 7 (extremely conform). The content validity index of each item is greater than 0.80 (Mean $=0.92$ ). The Cronbach's $\alpha$ of the entire scale is 0.84 and the $\alpha$ for the sense of organizational influence dimension is 0.69 ; the $\alpha$ for the other dimensions are equal or greater than 0.70 .

\section{Job satisfaction}

We measured job satisfaction with the Job Satisfaction Index described by Schreisheim and Tsui at the Western Management Institute Conference in 1980 [45]. The 6 items of it measure three dimensions, including general satisfaction (2 items), intrinsic satisfaction (2 items) and extrinsic satisfaction ( 2 items). Its six items are rated on a 5 -point Likert scale, ranging from 1 (strongly disagree) to 5 (strongly agree), with a higher total score indicating higher job satisfaction. The Cronbach's $\alpha$ of the scale is 0.73 . In this study, the Cronbach's $\alpha$ of the scale is 0.83 and the $\alpha$ of dimensions are $0.78,0.74$ and 0.75 respectively.

\section{Turnover intention}

We used the Nurse Turnover Intention Scale (NTIS) developed by Michael and Spector [46], which contains six items that measure three dimensions: possibility of resigning from present job (2 items); motivation to seek another job (2 items); and possibility of obtaining an external job (2 items). All the items were rated on a 4-point scale: never $=1$, seldom $=2$, occasionally $=3$, and often $=4$. The total average score $\leq 1$ indicates very low turnover intention, $>1$ and $\leq 2$ indicate low turnover intention, $>2$ and $\leq 3$ indicate high turnover intention, and $>3$ indicate very high turnover intention. The Cronbach's $\alpha$ of the scale is 0.77 and the content validity index is 0.68 . In this study, the Cronbach's $\alpha$ of the scale is 0.83 and the $\alpha$ of dimensions are $0.79,0.63$ and 0.72 respectively.

\section{Data analysis}

First, descriptive statistics were calculated for the sociodemographic characteristics, which are presented as frequency counts and percentages, and the main study variables (i.e., the four scales), which are presented as mean and standard deviation as the data were normally distributed. No missing data in valid questionnaire. Second, Pearson's correlation was used to test the associations between the main study variables. Next, multiple linear regression was performed with job satisfaction as the dependent variable in Model 1 and turnover intention as the dependent variable in Model 2. The independent variables included sociodemographic characteristics, hope, career identity, and job satisfaction (see the Results for details). These statistical analyses were conducted using SPSS version 24.0. The results were considered statistically significant when $p<0.05$. Finally, AMOS was used to conduct structural equation model (SEM), with turnover intention as the dependent variable, hope and career identity as independent variables, and job satisfaction as the mediating variable to test its mediating effect.

\section{Results}

Characteristics of the participants

The sociodemographic characteristics of the sample are displayed in Table 1. Almost all of the participants were female $(98.6 \%)$ and the average age was 31.8 years $(\mathrm{SD}=7.4)$. The majority were $25-44$ years of age $(75.3 \%)$ and married (65.3\%). More than half held a Bachelor's degree or higher (63.5\%), and most of them held a junior professional title $(71.4 \%)$ and no management position (94.3\%).

\section{Participants' hope, career identity, job satisfaction and turnover intention}

The descriptive statistics for hope, career identity, job satisfaction, and turnover are shown in Table 2. The average score of hope is $22.67 \pm 3.57$, and paths thinking scored higher than agency thinking $(11.77 \pm 1.83$ 
Table 1 Sociodemographic characteristics of the sample $(N=493)$

\begin{tabular}{|c|c|c|}
\hline & $n$ & $\%$ \\
\hline \multicolumn{3}{|l|}{ Age (years) } \\
\hline$<25$ & 76 & 15.4 \\
\hline $25-44$ & 371 & 75.3 \\
\hline$>44$ & 46 & 9.3 \\
\hline \multicolumn{3}{|l|}{ Gender } \\
\hline Female & 486 & 98.6 \\
\hline Male & 7 & 1.4 \\
\hline \multicolumn{3}{|l|}{ Marital status } \\
\hline Single & 160 & 32.5 \\
\hline Married & 322 & 65.3 \\
\hline Others & 11 & 2.2 \\
\hline \multicolumn{3}{|l|}{ Education level } \\
\hline Vocational education & 6 & 1.2 \\
\hline Advanced diploma & 174 & 35.3 \\
\hline Bachelor or higher & 313 & 63.5 \\
\hline \multicolumn{3}{|l|}{ Years of work } \\
\hline$<5$ & 145 & 29.4 \\
\hline $5-19$ & 266 & 54.0 \\
\hline$>19$ & 82 & 16.6 \\
\hline \multicolumn{3}{|l|}{ Professional title } \\
\hline Junior & 352 & 71.4 \\
\hline Senior or above & 141 & 28.6 \\
\hline \multicolumn{3}{|l|}{ Management position } \\
\hline None & 465 & 94.3 \\
\hline Officer or above & 28 & 5.7 \\
\hline \multicolumn{3}{|l|}{ Work unit } \\
\hline Surgical & 152 & 30.8 \\
\hline Medical & 173 & 35.1 \\
\hline Women \& Child & 37 & 7.5 \\
\hline Others & 131 & 26.6 \\
\hline
\end{tabular}

vs. $10.90 \pm 2.04)$. The average score of career identity is $110.22 \pm 19.16$, and the average score of items in sense of self efficiency dimension is the highest. The average score of job satisfaction is $20.71 \pm 4.55$, and the score of external satisfaction dimension is the highest. The average score of turnover intention is $15.54 \pm 3.77$, and the average score of items is greater than 2, indicating that the participants' turnover intention is at a high level.

\section{Associations among hope, career identity, job satisfaction,} and turnover intention

Pearson's correlations are shown in Table 3. Hope had a moderate positive correlation with career identity $(r=0.494)$ and job satisfaction $(r=0.421)$. We also found a positive relationship between career identity and job satisfaction $(r=0.610)$. There were negative correlations between turnover intention and hope $(r=-0.227)$, career identity $(r=-0.342)$, and job satisfaction $(r=-0.501)$. It is worth noting that was just small level of correlation between turnover intention and hope, while medium level with career identity.

Table 4 presents the results of the regression analysis, which further show the relationships between hope, career identity, job satisfaction, and turnover intention. Job satisfaction was the dependent variable in Model 1, and hope, career identity, age, and women \& children unit were the independent variables. Model 1 accounted for $42.5 \%$ of the variance in nurse's job satisfaction, and revealed that career identity predicted job satisfaction $(\beta=0.540)$ better than hope did $(\beta=0.159)$. Model 2 accounted for $32.4 \%$ of the variance in nurses' turnover intention (the dependent variable), with job satisfaction, vocational education, gender, women \& children unit, surgical unit, other unit, and marital status (married or not) as independent variables. Model 2 also shows that job satisfaction significantly predicted turnover intention $(\beta=0.500)$. Interestingly, the model found age was negatively associated with job satisfaction.

\section{Mediating effect of job satisfaction on the associations of career identity and hope with turnover intention}

Figure 2 and Table 5 show the SEM results. The final model and standardized model paths are shown in Fig. 2. The total effects, direct effects, and indirect effects are shown in Table 5. The model had a good fit with the data: RMSEA $=0.076, \quad G F I=0.920, \quad I F I=0.950, \quad T L I=0.935$, $\mathrm{NFI}=0.943, \mathrm{CMIN} / \mathrm{DF}=3.865$.

As shown in Table 5 , both hope $(\beta=-0.10$, for total effect) $)$ and career identity $(\beta=-0.38$, for total effect) had significant negative relationships with turnover intention. Figure 2 shows there was also a negative relationship between job satisfaction and turnover intention $(\beta=-0.54)$. The results also indicated that the indirect effect $(\beta=-0.09)$ of hope on turnover intention was significant as well as its direct effect on job satisfaction $(\beta=0.16)$. These findings mean that higher hope was related to lower turnover intention and higher job satisfaction, and that job satisfaction completely mediated the relationship between hope and turnover intention.

The results for career identity indicated that it had significant indirect $(\beta=-0.33)$ and direct $(\beta=-0.05)$ effects on turnover intention as well as its direct effect on job satisfaction $(\beta=0.60)$. These findings mean that higher career identity was related to lower turnover intention and higher job satisfaction and that job satisfaction completely mediated the relationship between career identity and turnover intention. 
Table 2 Descriptive statistics for the ADHS, NCIS, OJS, and ET

\begin{tabular}{|c|c|c|c|c|}
\hline Variables & Number of Items & Mean & SD & Cronbach's alpha \\
\hline $\mathrm{Hope}^{\mathrm{a}}$ & 8 & 22.67 & 3.57 & 0.857 \\
\hline Agency thinking & 4 & 10.90 & 2.04 & 0.779 \\
\hline Pathways thinking & 4 & 11.77 & 1.83 & 0.754 \\
\hline Career identity $^{b}$ & 21 & 110.22 & 19.16 & 0.949 \\
\hline Sense of grasp & 3 & 17.23 & 2.81 & 0.884 \\
\hline Sense of consistency & 4 & 21.55 & 4.44 & 0.892 \\
\hline Sense of significance & 3 & 15.39 & 3.27 & 0.739 \\
\hline Sense of self efficacy & 3 & 17.18 & 2.80 & 0.881 \\
\hline Sense of self decision & 3 & 14.59 & 4.02 & 0.851 \\
\hline Sense of organization's influence & 2 & 8.31 & 2.84 & 0.814 \\
\hline Sense of patients' influence & 3 & 15.97 & 3.30 & 0.806 \\
\hline Job satisfaction ${ }^{a}$ & 6 & 20.71 & 4.55 & 0.869 \\
\hline General satisfaction & 2 & 6.86 & 1.81 & 0.788 \\
\hline Intrinsic satisfaction & 2 & 6.14 & 1.89 & 0.740 \\
\hline Extrinsic satisfaction & 2 & 7.70 & 1.53 & 0.751 \\
\hline Turnover intention ${ }^{c}$ & 6 & 15.54 & 3.77 & 0.827 \\
\hline Possibility to resign from present job & 2 & 4.83 & 1.61 & 0.788 \\
\hline Motivation to seek another job & 2 & 4.87 & 1.63 & 0.629 \\
\hline Possibility to gained an external job & 2 & 5.84 & 1.27 & 0.724 \\
\hline
\end{tabular}

a 5 -point scale with a range of $1-5,{ }^{b} 7$-point scale with a range of $1-7,{ }^{c} 4$-point scale with a range of $1-4$

Table 3 Correlations between hope, career identity, job satisfaction, and turnover intention $(N=493)$

\begin{tabular}{llll}
\hline & $\mathbf{1}$ & $\mathbf{2}$ & $\mathbf{3}$ \\
\hline 1 Hope & - & - & - \\
2 Career identity & $0.494^{* * *}$ & - & - \\
3 Job satisfaction & $0.421^{* * *}$ & $0.610^{* * *}$ & - \\
4 Turnover intention & $-0.227^{* * *}$ & $-0.342^{* * *}$ & $-0.501^{* * *}$ \\
\hline${ }^{* * *} p<0.001$ & & &
\end{tabular}

\section{Discussion}

Our study found that hope and career identity were negatively correlated with turnover intention, and that job satisfaction and turnover intention were negatively correlated. Job satisfaction plays a completely mediating role on the associations of hope and career identity with turnover intention.

The average score of the NTIS was 15.54 ( $\mathrm{SD}=3.77)$ in this study, and $78.3 \%$ of nurses held a strong or extremely strong turnover intention. These results indicate a higher turnover intention compared to those reported in other similar studies. According to Rudman et al. [47], the 5-year cumulative incidence of nurses who strongly intended to leave the profession in Sweden was $30 \%$. In South Korea, the likelihood that new nursing school graduates would leave their first job within 3 years was $46 \%$ [48]. The WHO estimated in 2013 , that $40 \%$ of nurses might leave their work within a decade [49]. The situation in China is also not optimistic. The turnover intention rate of village doctors was $36.8 \%$ in 2014 [50], and $45.3 \%$ of township health inspectors have been found to have medium to high turnover intention [15]. The mean job satisfaction of nurses in the present study was $20.71(\mathrm{SD}=4.55)$, indicating that their job satisfaction was not very high, which is consistent with previous studies [51, 52]. Ghawadra et al., for example, found that $41 \%$ of hospital nurses had low job satisfaction [17]. A study of nurses in Turkey found their job satisfaction was at a moderate level [10].

The level of turnover intention of nurses in our study was higher than that reported in many previous studies and their job satisfaction was lower. The reason for this may lie in the nature of our sample, which consisted of registered nurses working in comprehensive tertiary hospitals in Beijing. Comprehensive tertiary hospitals in the Chinese capital have a very large flow of patients who have various diseases that are difficult to treat. Furthermore, the hospitals in our study were all affiliated with a university. Therefore, the nurses had to shoulder the responsibility for teaching nursing students in addition to their regular nursing duties. Thus, it is likely their work was more intensive and stressful, which may lead to lower job satisfaction and high turnover intention. Many studies have demonstrated the effects of high workloads and heavy stress on job satisfaction and turnover intention $[2$, 
Table 4 Regression results

\begin{tabular}{|c|c|c|c|c|c|c|}
\hline Independent variable & $B$ & $\beta$ & $t$ & $P$ & $R^{2}$ & $F$ \\
\hline Model 1 & & & & & 0.425 & $44.616^{* * *}$ \\
\hline Constant & 4.864 & - & 3.823 & $<0.001^{* * *}$ & & \\
\hline Women \& Child Unit & 1.578 & 0.092 & 2.496 & $0.013^{*}$ & & \\
\hline Age & -0.085 & -0.139 & -3.227 & $0.001^{* *}$ & & \\
\hline Career identity & 0.128 & 0.540 & 13.362 & $<0.001^{* * *}$ & & \\
\hline Hope & 0.201 & 0.159 & 3.926 & $<0.001^{* * *}$ & & \\
\hline Model 2 & & & & & 0.324 & $17.608^{* * *}$ \\
\hline Constant & 31.157 & - & 12.175 & $<0.001^{* * *}$ & & \\
\hline Married & 0.897 & 0.113 & 2.353 & $0.019^{*}$ & & \\
\hline Surgical Unit & 0.937 & 0.115 & 2.657 & $0.008^{* *}$ & & \\
\hline Women \& Child Unit & 1.281 & 0.090 & 2.211 & $0.028^{*}$ & & \\
\hline Other Unit & 0.884 & 0.104 & 2.657 & $0.018^{*}$ & & \\
\hline Gender & -3.456 & -0.109 & -2.353 & $0.005^{* *}$ & & \\
\hline Vocational education & -3.364 & -0.098 & -2.557 & $0.011^{*}$ & & \\
\hline Job Satisfaction & -0.415 & -0.500 & -10.068 & $<0.001^{* * *}$ & & \\
\hline
\end{tabular}

Model 1: dependent variable: Job satisfaction

Model 2: dependent variable: Turnover intention

$B$ Path coefficient, $\beta$ Standardized path coefficient, $R^{2}$ Coefficient determination, $t$ Path coefficient test statistics (critical ratio), $p$ Significance, $F$ Test for ANOVA ${ }^{*} p<0.05 ;{ }^{* *} p<0.01 ;{ }^{* * *} p<0.001$

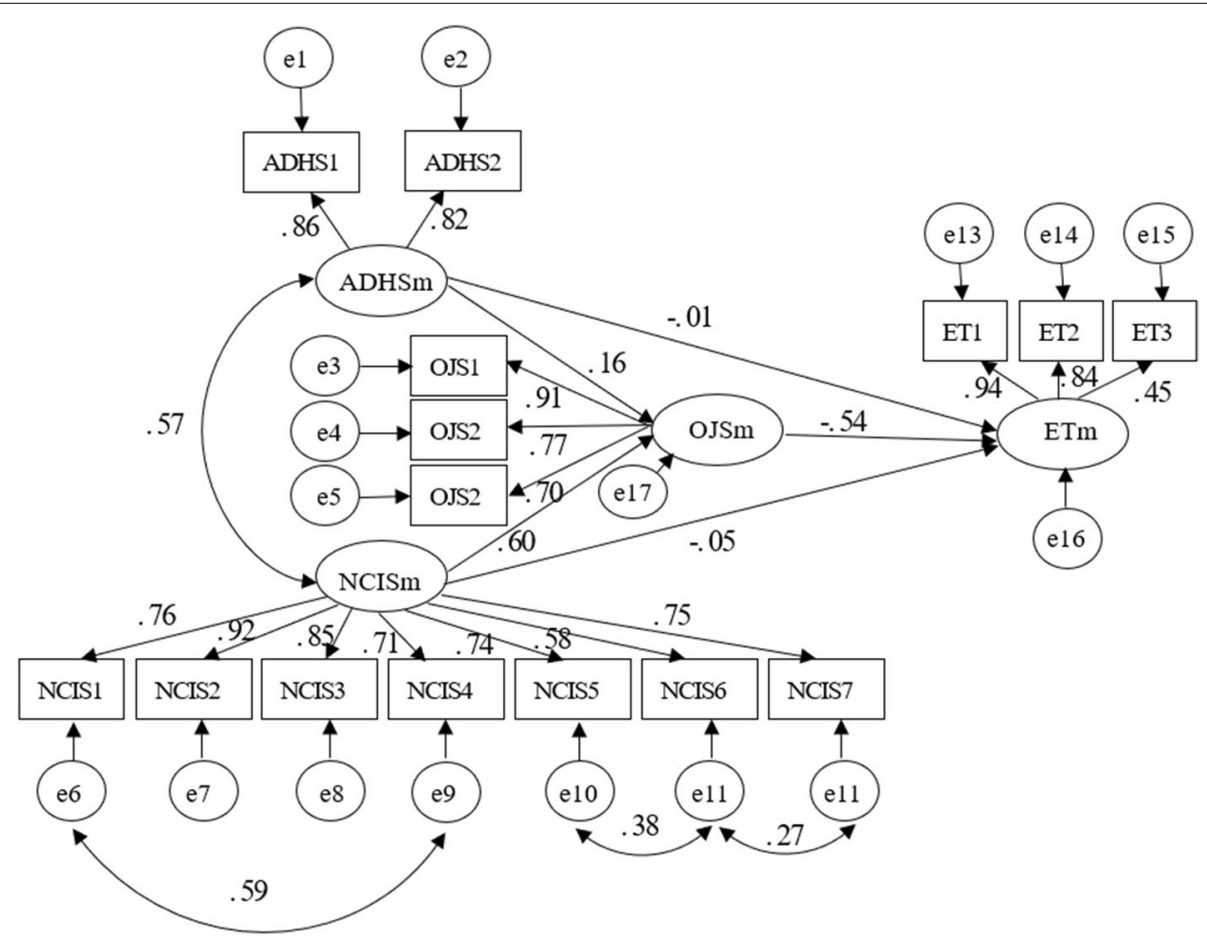

Fig. 2 Final model and standardized model paths. ADHSm: Hope; NCISm: career identity; OJSm: job satisfaction; ETm: Turnover; ADHS1: Agency thinking; ADHS2: Pathway thinking; NCIS1: Sense of grasp; NCIS2: Sense of consistency; NCIS3: Sense of significance; NCIS4: Sense of self efficacy; NCIS5: Sense of self decision; NCIS6: Sense of organization's influence; NCIS7: Sense of patients' influence; OJS1: General satisfaction; OJS2: Intrinsic satisfaction; OJS3: Extrinsic satisfaction; ET1: possibility to resign from present job; ET2: motivation to seek another job; ET3: possibility to gain an external job 
Table 5 Effects of hope and career identity on turnover intention

\begin{tabular}{|c|c|c|c|c|}
\hline Estimate & B & $\beta$ & SE & $95 \% \mathrm{Cl}$ \\
\hline \multicolumn{5}{|l|}{ Total effect } \\
\hline Career identity $\rightarrow$ Turnover intention & -0.23 & -0.38 & 0.06 & $(-0.49,-0.26)$ \\
\hline Hope $\rightarrow$ Turnover intention & -0.08 & -0.10 & 0.09 & $(-0.23,-0.03)$ \\
\hline \multicolumn{5}{|l|}{ Indirect effect } \\
\hline Career identity $\rightarrow$ Job satisfaction $\rightarrow$ Turnover intention & -0.21 & -0.33 & 0.05 & $(-0.45,-0.23)$ \\
\hline Hope $\rightarrow$ Job satisfaction $\rightarrow$ Turnover intention & -0.08 & -0.09 & 0.04 & $(-0.17,-0.03)$ \\
\hline \multicolumn{5}{|l|}{ Direct effect } \\
\hline Career identity $\rightarrow$ Turnover intention & -0.03 & -0.05 & 0.07 & $(-0.18,0.09)$ \\
\hline Hope $\rightarrow$ Turnover intention & -0.01 & -0.01 & 0.06 & $(-0.12,0.11)$ \\
\hline
\end{tabular}

A 95\% bootstrap confidence interval that does not include zero means an effect is significant

$5,17]$, suggesting that nursing managers should pay more attention to these problems.

Our analyses revealed both career identity and hope were negatively associated with turnover intention. Career identity has a significant association with turnover intention, and it provides a type of intrinsic support. Nurses will devote more energy in and be more enthusiastic about their work when they positively identify with their careers. Career identity may help them to overcome the difficulties and problems that lead to dissatisfaction and strengthen their commitment to stay. Nurses with poor career identity usually tend to leave. Generally speaking, by improving employees' professional identity, employees' turnover intention can be effectively reduced. When employees believe that their work can create value and make sense to themselves, they have a higher sense of career identity, more investment and satisfaction with their work; Otherwise, when the career identity is low, employees will consider leaving their existing jobs when appropriate opportunities arise [53, 54]. Furthermore, research has revealed that career identity can influence turnover intention through direct and indirect pathways $[8,15,18]$. Hope and career identity are expressions of intrinsic motivation, which explains why nurses with higher career identity tend to have a positive outlook towards work and retain their hope, thereby having positive effects on many aspects of professional development. A recent quantitative study found widespread pressure on the nurses who helped fight against COVID-19 in Hubei [55]. These nurses mainly had to stay alone in their rooms after work for the sake of safety. The professional identity and hope of nurses were particularly important in this psychological state of pressure and social isolation. Otherwise, this situation would have easily made them think of leaving.

The results of the SEM in our study showed that job satisfaction had a completely mediating effect on the association between career identity and turnover intention.
This result is consistent with previous research that job satisfaction had an intermediary role in the relationship between career identity and turnover intention [15]. Job satisfaction is the key incentive variable that determines employees' turnover intention behavior. In the workplace, employees conduct personal assessment of work characteristics and work environment to generate cognition, emotion and intention, so as to determine their positive or negative evaluation of the nature of work and even the company $[56,57]$. This study promotes the development of career identity literature by investigating the intermediary mechanism between career identity and turnover intention. Although early studies have concluded that job satisfaction is a key outcome variable in the process of professional identity $[10,58]$, previous scholars rarely empirically tested the mediating role of job satisfaction in nurses. Our research shows that job satisfaction is an important way to connect career identity with turnover intention. In addition, we found job satisfaction was an intermediate variable between hope and turnover intention. A previous study showed that psychological capital had a medium to large indirect effect on employees' turnover intention when hope was part of psychological capital [59]. These results suggest that we can take effective measures to enhance nurses' hope and career identity so as to improve their job satisfaction and ultimately reduce their turnover intention.

Our study extends prior research results and provides nursing managers with suggestions for team building and management that have theoretical and practical significance. In the face of increasing demands on nurses, the nursing shortage, and proposals to increase the quality of nursing care, nursing managers need to think about how to reduce turnover, retain clinical nurses, and improve the quality of nursing. As discussed above, job satisfaction appears to reduce turnover intention, and to mediate the apparent effects of career identity and hope on turnover intention. 
Career identity and hope can affect turnover intention directly and indirectly through job satisfaction. Strengthening career identity and improving hope are critical measures for nursing managers to improve nurses' job satisfaction, lower turnover intention, and thereby reduce turnover rate and improve the quality of care. Career identity cognitively influences nurses' attitudes about work. This influence begins when a student enters nursing education and continues throughout his/her working life [18]. Strengthening nurses' career identity through educational programs is feasible because nurses who did not sufficiently develop career identities during their vocational education can still develop them [18]. In addition, colleges should pay more attention to instilling nursing students with career identity and nursing values [3]. The gap between college and clinical work is one of the reasons for the low level of career identity in newly graduated nurses. Providing them with adequate guidance and support, and enabling them to practice with confidence in a safe and proficient manner may increase their career identity with nursing during this transitional period.

The increased recognition of nurses' practice is important for expanding the nursing workforce in the future. Hope is influenced by many factors, such as reward, workload, working conditions, doctor-nurse relationships, and management style. Management should increase nurses' level of hope and job satisfaction in order to retain them by improving their working conditions $[17,60]$. This is cost-effective, since training nurses is costly and resources can be directed from being wasted efforts to productive activities [47]. Furthermore, providing nurses with more support, helping them find a spiritual foundation [17], and holding mindful activities that stimulate positive emotions are helpful for improving nurses' level of hope. Of course, increasing one's entire psychological capital is beneficial for having hope play a role in professional development.

\section{Limitations}

Our study has some limitations. First, though the sample was large and representative, the generalizability of its results is limited because the sample came from tertiary hospitals in Beijing, all of which were comprehensive teaching hospitals of medical colleges, and thus, these nurses may have characteristics that increase turnover intention. Therefore, further research should be conducted with samples taken from a broader population of nurses (such as nurses from other cities or hospitals of different grades). Second, though the current findings found job satisfaction mediated the association between hope and turnover intention, other variables may contribute to this effect (for instance, social support may influence the relationships among these variables). Future studies should explore other possible mediating variables to reach a more definitive conclusion. Last but not least, because the mediating effect implies causality, it is lack of sufficient persuasion to verify the mediating effect with cross-sectional data. Therefore, the mediating effect explored in this study needs further experimental verification.

\section{Conclusions}

The results of this study support the relationship among hope, career identity, job satisfaction and turnover intention, which guide the intervention measures driven by theory to solve the problem of high turnover intention of nursing staff and help to solve the shortage of nurses. Thus, we can take effective measures to enhance nurses' hope and career identity in order to improve their job satisfaction and ultimately their turnover intention. Providing nurses with more support, helping them find a spiritual foundation, and holding mindful activities that stimulate positive emotions are helpful. In addition, colleges should pay more attention to instilling nursing students with career identity and nursing values.

\section{Abbreviations \\ STROBE statement: Strengthening the Reporting of Observational studies in Epidemiology (STROBE) statement; WHO: World Health Organization; SEM: Structural Equation Model; ADHS: Adult Dispositional Hope Scale; NCIS: Nurs- ing Career Identity Scale; NTIS: Nurse Turnover Intention Scale; SPSS: Statistical Product and Service Solutions; SD: Standard Deviation; COVID-19: Corona Virus Disease-19.}

\section{Acknowledgements}

The authors thank all the nurses who participated in the study.

\section{Authors' contributions}

$C K, W ; Y, L$ and $X, W$ design the study. $C K, W ; Y, L$ and $H L, H$ performed data collection and analysis. $\mathrm{HL}, \mathrm{H} ; \mathrm{CK}, \mathrm{W}$ and $\mathrm{Y}, \mathrm{L}$ were major contributors in writing the manuscript and $\mathrm{HL}, \mathrm{H}$ and $\mathrm{X}, \mathrm{W}$ performed critical revisions for important intellectual content. All authors read and approved the final manuscript.

\section{Funding}

This research was funded by the National Natural Science Foundation of China under Grant No.72071004 \& No.71601004, National Key R\&D Program of China under Grant No.2020YFC2008805 \& No.2020YFC2008800, and the Undergraduate Innovative Research Project under Grant No. BJMU-HL-201808D. The funders did not play any role in the study.

Availability of data and materials

The datasets used and/or analysed during the current study are available from the corresponding author on reasonable request.

\section{Declarations}

\section{Ethics approval and consent to participate}

The study was approved by Peking University Institutional Review Board and the number is IRB00001052-19047. The guiding words of the questionnaire filled in by the participants were as follows: filling in the questionnaire was regarded as informed consent. Therefore, the authors consider that written informed consent was obtained from the participants. 


\section{Consent for publication}

Not applicable.

\section{Competing interests}

The authors declare that they have no competing interests.

Received: 13 October 2020 Accepted: 1 February 2022 Published online: 10 February 2022

\section{References}

1. Chang H-Y, Huang T-L, Wong AM-K, Ho L-H, Juan Y-C, Chen Y-F, et al. How career facilitators and barriers influence nurses' professional turnover intention. J Adv Nurs. 2019;75(12):3577-87.

2. Fasbender U, Van der Heijden BIJM, Grimshaw S. Job satisfaction, job stress and nurses' turnover intentions: the moderating roles of on-the-job and off-the-job embeddedness. J Adv Nurs. 2019;75(2):327-37.

3. Wang $\mathrm{E}, \mathrm{Hu} \mathrm{H}, \mathrm{Mao} \mathrm{S}$, Liu H. Intrinsic motivation and turnover intention among geriatric nurses employed in nursing homes: the roles of job burnout and pay satisfaction. Contemp Nurse. 2019;55(2-3):195-210.

4. Chenevert D, Jourdain $\mathrm{G}$, Vandenberghe $\mathrm{C}$. The role of high-involvement work practices and professional self-image in nursing recruits' turnover: a three-year prospective study. Int J Nurs Stud. 2016:53:73-84.

5. Lo W-Y, Chien L-Y, Hwang F-M, Huang N, Chiou S-T. From job stress to intention to leave among hospital nurses: a structural equationmodelling approach. J Adv Nurs. 2018;74(3):677-88.

6. Sawatzky J-AV, Enns CL. Exploring the key predictors of retention in emergency nurses. J Nurs Manag. 2012;20(5):696-707.

7. Wan Q, Li Z, Zhou W, Shang S. Effects of work environment and job characteristics on the turnover intention of experienced nurses: the mediating role of work engagement. J Adv Nurs. 2018;74(6):1332-41.

8. WHO. Global strategy on human resources for health: Workforce 2030 2016. https://www.who.int/hrh/resources/16059_Global_strategyWorkfor ce2030.pdf. Accessed 15 May 2020.

9. Kaihlanen A-M, Elovainio M, Haavisto E, Salminen L, Sinervo T. Final clinical practicum, transition experience and turnover intentions among newly graduated nurses: a cross sectional study. Nurse Educ Today. 2020;84:104245.

10. Sabanciogullari S, Dogan S. Relationship between job satisfaction, professional identity and intention to leave the profession among nurses in Turkey. J Nurs Manag. 2015;23(8):1076-85.

11. Yun MR, Yu B. Strategies for reducing hospital nurse turnover in South Korea: nurses' perceptions and suggestions. J Nurs Manag. 2021;29(5):1256-62.

12. Huang T-L, Wong M-K, Shyu Y-IL, Ho L-H, Yeh J-R, Teng C-I. Reducing turnover intention to improve care outcome: a two-wave study. J Adv Nurs. 2021:77(7):3083-92

13. Sousa-Poza A, Henneberger F. Analyzing job mobility with job turnover intentions: an international comparative study. J Econ Issues. 2004;38(1):113-37.

14. Tett RP, Meyer JP. Job satisfaction, organizational commitment, turnover intention, and turnover: path analyses based on meta-analytic findings. Pers Psychol. 1993;46(2):259-93.

15. Zhang W, Meng H, Yang S, Liu D. The influence of professional identity, job satisfaction, and work engagement on turnover intention among township health inspectors in China. Int J Environ Res Public Health. 2018;15(5):988.

16. Griffeth RW, Hom PW, Gaertner S. A meta-analysis of antecedents and correlates of employee turnover: update, moderator tests, and research implications for the next millennium. J Manag. 2000;26(3):463-88.

17. Ghawadra SF, Abdullah KL, Choo WY, Phang CK. Psychological distress and its association with job satisfaction among nurses in a teaching hospital. J Clin Nurs. 2019:28(21-22):4087-97.

18. Sabanciogullari S, Dogan S. Effects of the professional identity development programme on the professional identity, job satisfaction and burnout levels of nurses: a pilot study. Int J Nurs Pract. 2015;21(6):847-57.

19. Van Camp J, Chappy S. The effectiveness of nurse residency programs on retention: a systematic review. AORN J. 2017;106(2):128-44.
20. Tonges MC, Rothstein H, Carter HK. Sources of satisfaction in hospital nursing practice. A guide to effective job design. J Nurs Adm. 1998:28(5):47-61.

21. Laschinger HK, Finegan J, Shamian J, Wilk P. Impact of structural and psychological empowerment on job strain in nursing work settings: expanding Kanter's model. J Nurs Adm. 2001;31(5):260-72.

22. Moore M, Hofman JE. Professional identity in institutions of higher-learning in Israel. High Educ. 1988;17(1):69-79.

23. Ferrell C, Christian R, Rachel M. Registered nurse experiences of nursing professional identity: a qualitative systematic review protocol. JBI Database System Rev Implement Rep. 2017;15(12):2866-70.

24. Morrow MR. Knowledge development in nursing: theory and process (10th ed). Nurs Sci Q. 2020;33(4):362-3.

25. Scanlan JN, Hazelton T. Relationships between job satisfaction, burnout, professional identity and meaningfulness of work activities for occupational therapists working in mental health. Aust Occup Ther J. 2019;66(5):581-90.

26. Coetzee M, van Dyk J. Workplace bullying and turnover intention: exploring work engagement as a potential mediator. Psychol Rep. 2018;121(2):375-92.

27. Wang C, Xu J, Zhang TC, Li QM. Effects of professional identity on turnover intention in China's hotel employees: the mediating role of employee engagement and job satisfaction. J Hosp Tour Manag 2020;45:10-22.

28. Avey JB, Reichard RJ, Luthans F, Mhatre KH. Meta-analysis of the impact of positive psychological capital on employee attitudes, behaviors, and performance. Hum Resour Dev Q. 2011;22(2):127-52.

29. Ayijiamali S, Wang HC, Wang MX. Study on relationship between psychological capital and turnover intention of nurses in a three grade A hospital in Urumqi city. Chin Nurs Res. 2014;28(11):1299-301.

30. Zou Y, Yang Y, Qiu XH, Yang XX, Qiao ZX, Wang M, et al. Path analysis of the influence of nurses' psychological capital, professional identity and organizational commitment on the turnover intention in Harbin hospital. Med Soc. 2020;33(1):116-9,42.

31. Snyder CR. Conceptualizing, measuring, and nursing hope. J Couns Dev. 1995:73(3):355-60.

32. Hirschi A. Hope as a resource for self-directed career management: investigating mediating effects on proactive career behaviors and life and job satisfaction. J Happiness Stud. 2014;15(6):1495-512.

33. Wang H, Qiao Y, Li X. In: Duysters G, DeHoyos A, Kaminishi K, editors. Research on the correlation between psychological capital and turnover intention; 2012. p. 774-+

34. Alsaraireh F, Griffin MTQ, Ziehm SR, Fitzpatrick JJ. Job satisfaction and turnover intention among Jordanian nurses in psychiatric units. Int J Ment Health Nurs. 2014;23(5):460-7.

35. Freund A. Commitment and job satisfaction as predictors of turnover intentions among welfare workers. Adm Soc Work. 2005;29(2):5-21.

36. Jenkins M, Paul Thomlinson R. Organisational commitment and job satisfaction as predictors of employee turnover intentions. Manag Res News. 1992;15(10):18-22.

37. Hoppock R. Job satisfaction. New York: Harper \& Brother Publisher; 1935

38. Duggleby W, Cooper D, Penz K. Hope, self-efficacy, spiritual well-being and job satisfaction. J Adv Nurs. 2009:65(11):2376-85.

39. Hirschi A, Jaensch VK, Herrmann A. Protean career orientation, vocational identity, and self-efficacy: an empirical clarification of their relationship. Eur J Work Organ Psychol. 2017;26(2):208-20.

40. Klein DF. Beyond significance testing: reforming data analysis methods in behavioral research. Am J Psychiatry. 2005;162(3):643-a-4.

41. von E. Strengthening the reporting of observational studies in epidemiology (STROBE) statement: guidelines for reporting observational studies (vol 335, pg 806, 2007). BMJ. 2008;336(7634):35.

42. Snyder CR, Harris C, Anderson JR, Holleran SA, Irving LM, Sigmon ST, et al. The will and the ways - development and validation of an individualdifferences measure of hope. J Pers Soc Psychol. 1991:60(4):570-85.

43. Chen C, Shen H, Li X. Reliability and validity of adult dispositional hope scale. Chin J Psychol. 2009:17(1):24-6.

44. Zhao H, Lu T, Zhang C, Deng F, Zheng J, Da X, et al. Testing for reliability and validity of Chinese version of the nurse's career identity scale. Chin Nurs Manag. 2010;10(11):49-51. 
45. Schriesheim C, Tsui AS. Development and validation of a short satisfaction instrument for use in survey feedback interventions. Buffalo: Paper presented at the western meeting of Academy of management; 1980.

46. Michaels C, Spector P. Causes of employee turnover: a test of the Mobley, Griffeth, hand, and Meglino model. J Appl Psychol. 1982;67:53-9.

47. Rudman A, Gustavsson P, Hultell D. A prospective study of nurses' intentions to leave the profession during their first five years of practice in Sweden. Int J Nurs Stud. 2014;51(4):612-24.

48. Cho S-H, Lee JY, Mark BA, Yun S-C. Turnover of new graduate nurses in their first job using survival analysis. J Nurs Scholarsh. 2012;44(1):63-70.

49. WHO. Global health workforce shortage to reach 12.9 million in coming decades. 2013. https://www.who.int/mediacentre/news/releases/2013/ health-workforce-shortage/en/ Accessed 15 May 2020.

50. Fang $P$, Liu X, Huang L, Zhang X, Fang Z. Factors that influence the turnover intention of Chinese village doctors based on the investigation results of Xiangyang City in Hubei Province. Int J Equity Health. 2014;13(1):1-9.

51. Anselmo-Witzel S, Orshan SA, Heitner KL, Bachand J. Are generation $Y$ nurses satisfied on the job? Understanding their lived experiences. J Nurs Adm. 2017:47(4):232-7.

52. Roney LN, Acri MC. The cost of caring: an exploration of compassion fatigue, compassion satisfaction, and job satisfaction in pediatric nurses. J Pediatr Nurs. 2018:40:74-80.

53. Poon JML. Effects of performance appraisal politics on job satisfaction and turnover intention. Pers Rev. 2004;33(3):322-34.

54. Applebaum D, Fowler S, Fiedler N, Osinubi O, Robson M. The impact of environmental factors on nursing stress, job satisfaction, and turnover intention. J Nurs Adm. 2010;40(7-8):323-8.

55. Mo Y, Deng L, Zhang L, Lang Q, Liao C, Wang N, et al. Work stress among Chinese nurses to support Wuhan in fighting against COVID-19 epidemic. J Nurs Manag. 2020;28(5):1002-9.

56. French FH, Andrew JE, Awramenko M, Coutts H, Leighton-Beck L, Mollison J, et al. Consultants in NHS Scotland: a survey of work commitments, remuneration, job satisfaction and retirement plans. Scott Med J. 2004;49(2):47-52.

57. Devery H, Scanlan JN, Ross J. Factors associated with professional identity, job satisfaction and burnout for occupational therapists working in eating disorders: a mixed methods study. Aust Occup Ther J. 2018;65(6):523-32.

58. Provan DJ, Dekker SWA, Rae AJ. Benefactor or burden: exploring the professional identity of safety professionals. I Saf Res. 2018;66:21-32.

59. Amunkete S, Rothmann S. Authentic leadership, psychological capital, job satisfaction and intention to leave in state-owned enterprises. J Psychol Afr. 2015;25(4):271-81.

60. Han J, Kang H-J, Kwon GH. Impact of intelligent healthscape quality on nurse job outcomes and job satisfaction: a test of the moderating effect of innovativeness. J Nurs Manag. 2020;28(1):43-53.

\section{Publisher's Note}

Springer Nature remains neutral with regard to jurisdictional claims in published maps and institutional affiliations.

Ready to submit your research? Choose BMC and benefit from:

- fast, convenient online submission

- thorough peer review by experienced researchers in your field

- rapid publication on acceptance

- support for research data, including large and complex data types

- gold Open Access which fosters wider collaboration and increased citations

- maximum visibility for your research: over 100M website views per year

At BMC, research is always in progress.

Learn more biomedcentral.com/submissions 